
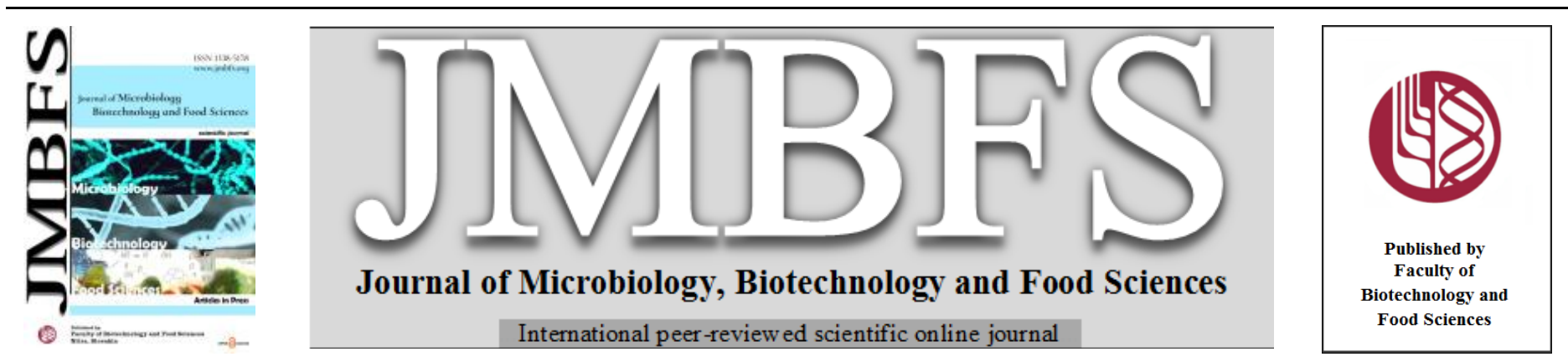

\title{
DEVELOPMENT OF HUMAN INTERLEUKIN-7 IMMUNOAFFINITY PURIFICATION METHOD
}

\author{
Yurii Gorshunov $^{1,2}$, Tetiana Lutsenko ${ }^{1,3}$, Alexander Besarab $^{1 *}$, Ievgen Nastenko $^{1}$
}

\author{
Address $(e s)$ : \\ ${ }^{1}$ National Technical University of Ukraine "Igor Sikorsky Kyiv Polytechnic Institute”, Department of Translational Medical Bioengineering, Peremohy av., 37,03056 \\ Kyiv, Ukraine. \\ ${ }^{2}$ Research and Design-Technological Institute of Municipal Economy, Urytsky str., 35, 03035 Kyiv, Ukraine.
}

${ }^{3}$ UA Pro-Pharma LLC, Peremohy str., 9, 03170 Kyiv, Ukraine.

*Corresponding author: abv2507@gmail.com

https://doi.org/10.55251/jmbfs.4338

\section{ARTICLE INFO}

Received 14. 2. 2021

Revised 21. 1. 2022

Accepted 25. 1.2022

Published 1. 6. 2022

Regular article

OPEN $\partial_{\text {ACCESS }}$

\section{ABSTRACT}

The article presents the results of the comparative development of different variants of immunoaffinity sorbents for the purification of human IL-7, namely: Sepharose 6B and sol-gel materials based on tetraethoxysilane (TEOS). The optimal conditions for the synthesis of a chromatographic sorbent based on TEOS, which provide acceptable characteristics of the immobilization of a biological substance, were experimentally established. The sorbent based on TEOS and Sepharose 6B provide identical characteristics for the sorption of antibodies after 12 hours of the experiment. To establish rational conditions for immunoaffinity chromatography, various combinations of sorbents, anti-IL-7 monoclonal antibodies, and elution solutions were studied. It was shown that a variant of immunoaffinity chromatography based on TEOS sorbent using 325D2 anti-IL-7 monoclonal antibodies and 4M magnesium chloride solution as eluate, is more effective. Immunochromatographic columns synthesized on the basis of Sepharose 6B and TEOS are characterized by high recovery rates (at least $95 \%)$ in a wide range of human IL-7 concentrations $(0.05 \ldots 20 \mu \mathrm{g} / \mathrm{ml})$, however, the column based on Sepharose 6B is less than stable with repeated use (more than 12 cycles without regeneration). The developed method makes it possible to obtain recombinant human IL-7 with a purity of $98 \%$.

Keywords: immunoaffinity chromatography, sorbents, human interleukin-7, monoclonal antibodies

\section{INTRODUCTION}

Interleukin-7 (IL-7) is an immune cytokine, playing crucial role in development and homeostasis of B and T cells; taking part in development of dendritic cells, NK cells and inducer cells of lymphoid cells which are an important part of immune system. IL-7 is capable of regulating immune system homeostasis due to its ability to handle balance between processes of apoptosis and proliferation of thymocytes, naïve T cells and memory cells. This is how IL-7 provides consistency of number and functional activity of these populations (Slyvka et al., 2014; Grigorieva et al., 2019; Galkin et al., 2017a).

Recombinant proteins, which are intended to be used in medicine for curative purposes, shall correspond to specific requirements, distinguishing them from those proteins used for scientific and research purposes only (Lutsenko et al., 2017; Natochii et al., 2019; Sokol et al., 2020a). At the same time special conditions of recombinant protein's application result in quite specific standardization conditions. One of the elements of quality assurance of recombinant medicine of therapeutic use is application of highly specific and effective methods of recombinant proteins' extraction and purification (Galkin et al., 2017a; Lutsenko et al., 2017; Natochii et al., 2019).

A wide range of methods, applied in molecular immunology and biochemistry, are used to extract and purify recombinant proteins. The aforementioned methods are based on the usage of physical, chemical and biological peculiarities of corresponding biomolecules (Galkin et al., 2019; Nikolaenko et al., 2007). The methods which are applied the most are gel-filtration, ion-exchange and immunoaffinity chromatographies. The majority of methods, mentioned in literature, envisage the application of several methods (Natochii et al., 2019; Motronenko et al., 2020; Pokynbroda et al., 2019). The most specific method is immunoaffinity chromatography itself with application of highly specific and monoclonal affine antibodies (MAbs). During the previous stages of our research we have obtained and characterized MAbs panel for IL-7, which provided the possibility to develop corresponding bioanalytical methods.

The aim of the study was to compare different immunoaffinity sorbents with the view to extract recombinant human IL-7 and then - to develop corresponding chromatographic method.

\section{MATERIALS AND METHODS}

Obtainment of sepharose-based immunoaffininy sorbent was performed according to basic method (Nikolaenko et al., 2007). $25 \mathrm{ml}$ of sepharose suspension 6B («Sigma», USA) were deterged in a glass filter and transferred into a $100 \mathrm{ml}$ shaking flask. $25 \mathrm{ml}$ of carbonate buffer ( $\mathrm{pH} \mathrm{11)}$ were added to sepharose along with $6.25 \mathrm{ml}$ of divinyl sulpfone («Sigma», USA) and had been shaken in a shaker for 80 minutes. Activated carrier was filtrated in a glass filter, deterged with water and resuspended in $15 \mathrm{ml}$ of purified MAbs' solution with the concentration being $5.3 \mathrm{mg} / \mathrm{ml}$ in $0.1 \mathrm{M}$ of carbonate buffer ( $\mathrm{pH} 9.2$ ). The suspension had been shaken at r.t. for 12 hours.

Control of IAS (IAS = immunoaffinity sorbent) synthesis was performed via studying of kinetics of MAbs immobilization on sepharose. In order to do it we collected $50 \mathrm{mcl}$ of supernatant liquid from reaction mixture every 30 minutes within 4 hours and after 6 and 12 hours from the beginning of immobilization correspondingly. Intact MAbs incubated in carbonate buffer at r.t. were used as control samples. Upon selection all the samples were cooled down and analyzed via ELISA method (ELISA = Enzyme-Linked Immunosorbent Assay) (Galkin et $a l ., 2017 b)$. In order to do it recombinant human IL-7 was sorbed on ELISA-plates, parent antibodies and selected samples were diluted and tittered. Upon incubation and deterging anti-species conjugate (rabbit polyclonal antibodies, conjugated with horseradish peroxidase) and chromogen were added; results were calculated with spectrophotometer. In accordance with obtained ELISA results we designed the graphs of correlation between values of optical density values of reaction mixture's samples and period of incubation.

Upon conclusion of synthesis for inactivation of groups which didn't react the carrier was filtered, deterged with water, suspended in $25 \mathrm{ml}$ of $0.1 \mathrm{M}$ carbonate buffer containing $1.5 \mathrm{ml}$ of ETA and then it had been shaken for 2 hours. Sepharose was filtered in a glass filter, deterged with water and suspended in a phosphate buffer. Prepared IAS was stored for further usage at $4{ }^{\circ} \mathrm{C}$.

Obtainment of immunoaffinity sorbent wich based on tetraethoxysilane was performed according to basic method (Altstein et al., 2001). In order to obtain solgel we mixed $0.23 \mathrm{ml}$ of alkylsilane, $0.23 \mathrm{ml}$ of $0.0025 \mathrm{M}$ chlorohydric acid (accelerant), $0.04 \mathrm{ml}$ of $10 \%$ polyethyleneglycole (PEG-400) with mole ratio $\mathrm{H}_{2} \mathrm{O}: \mathrm{Si}=8: 1$. The mixture had been shaken for 1 minute until transparent homogenous mixture was obtained. The prepared solution was then kept in an 
ultrasonic bath at $20-25^{\circ} \mathrm{C}$ for 30 minutes. The sythesised prehydrolisate was used as a matrix for antibodies' introduction during the next stage of IAS obtainment Antibodies were diluted with phosphate-buffered saline (PBS), pH 7.2-7.4 until the ratio was $1: 100$. Then $0.5 \mathrm{ml}$ of antibodies was added to prehydrolisate. Everything had been meticulously mixed for 5 minutes and kept until complete sol-gel transition at r.t. for 10 minutes. Obtained gel was deterged with $2 \mathrm{ml}$ of PBS Optimal characteristics of sol-gel material were revealed during the $2^{\text {nd }}$ day of maturation. Then gel ( $0.27 \mathrm{~g}$ equivalent to dried gel) was dispersed and placed into a standard column for solid-phase extraction between two porous filters. Obtained IAC (IAC = immunoaffinity column) was deterged with $50 \mathrm{ml}$ of PBS Gel with immobilized MAbs was stored under layer of PBS at $4{ }^{\circ} \mathrm{C}$.

Calculating of human IL-7 concentration. Concentration of human IL-7 in samples was calculated via biological method using peripheral mononuclear blood cells (PMBC) (Lutsenko et al., 2017). The blood was obtained from verified donors with such anticoagulating agent as heparine (10 units $/ \mathrm{ml}$ of blood were used). With the cell separation medium Histopaque 1077 (Sigma) we conducted separation of blood in a benchtop laboratory centrifuge with rotor (Liston 2204 Classic) at 1500 rpm at r.t. for 30 minutes. We have collected PMBC with an aceptic syringe and conducted double deterging of cells in $10 \mathrm{ml}$ of deterging medium (RPMI-1640 (Biowest), with inclusion of $2 \%$ of fetal calf serum, via centrifugation at $400 \mathrm{~g}$ $(1000 \mathrm{rpm})$ at r.t. for 10 minutes. The cells were resuspended in $4 \mathrm{ml}$ of cultivating medium (RPMI with $10 \%$ fetal calf cerum, $10 \mu \mathrm{g} / \mathrm{ml}$ of PHA (PHA Sigma L 8754) and $50 \mathrm{Mm}$ of mercaptoethanol). We conducted the calculation of living cells during staining with $0.4 \%$ trypan blue in Gorjaev chamber. We managed the concentration of cells to $(1-4) \times 10^{6} \mathrm{cell} / \mathrm{ml}$ in cultivating medium, and cultivated on beddings $\mathrm{T} 45\left(10 \mathrm{ml} /\right.$ bedding) at $37^{\circ} \mathrm{C}$ in incubator with $5 \%$ of $\mathrm{CO}_{2}$ for 5 days Upon PHA stimulation the suspension of cells has been centrifugated at $1000 \mathrm{rpm}$ for 10 minutes. We have also conducted one more deterging stage as it was stated before. Cells were resuspended in $3-5 \mathrm{ml}$ of cultivating medium. Then we calculated the number of living cells upon staining with $0.4 \%$ trypan blue in Gorjaev chamber. The concentration was gradated to $2 \times 10^{6}$ cell $/ \mathrm{ml}$. The cells were put into 96-well plate with $50 \mathrm{mcl}$ put in each well (Sokol et al., 2020b).

Recombinant IL-7 (rIL-7), produced by "PeproTech" was used a standard. We conducted the dilution in phosphate buffer $\mathrm{pH} 7.4$ with inclusion of $0.1 \%$ calf seralbumin up to the concentration ratio being $1 \mathrm{ng} / \mu \mathrm{l}$ - solution No.1. We prepared the following cultures out of Solution No.1: $0.125 \mathrm{ng}, 0.25 \mathrm{ng}, 0.5 \mathrm{ng}$, $1 \mathrm{ng}, 2 \mathrm{ng}, 3 \mathrm{ng}, 4 \mathrm{ng}, 5 \mathrm{ng}, 6 \mathrm{ng}$ in $\mathrm{ml}$ in medium for PMBC cultivation.

The studied samples were prepared from dilution in phosphate buffer $\mathrm{pH} 7.4$ with inclusion of $0.1 \%$ calf seralbumin up to the concentration ratio being $1 \mathrm{ng} / \mathrm{mcl}$ solution No.1 We prepared the following cultures out of Solution No.1: $0.25 \mathrm{ng}$, $0.5 \mathrm{ng}, 2 \mathrm{ng}, 5 \mathrm{ng}, 10 \mathrm{ng}, 20 \mathrm{ng}, 30 \mathrm{ng}, 40 \mathrm{ng}, 50 \mathrm{ng}$ in $\mathrm{ml}$ in the medium for PMBC cultivation.

Obtained cultures of standard and samples were transferred in $50 \mu 1$ into well of plates with PMBC for 3 times; the plates were incubated in the incubator at $37^{\circ} \mathrm{C}$ with $5 \% \mathrm{CO}_{2}$ for 4 days. Upon that we added $15 \mu \mathrm{l}$ of MTT solution $(5 \mathrm{mg} / \mathrm{ml})$ in each well and had been incubating them in the incubator at $37^{\circ}$ with $5 \% \mathrm{CO}_{2}$ for 4 hours. Then with the view to dissolve formazan crystals we added $200 \mu \mathrm{l}$ of dimethyl sulfoxide (DMSO) in each well. Optical density was measured at $570 \mathrm{~nm}$ We have designed a calibration curve and calculated the IL-7 concentration.

\section{RESULTS}

Our previous studies provide scientific justification and methods of non-specific chromatographic extraction and purification of IL-7 (Motronenko et al., 2020). In case of specific immunochemical reagents, i.e. MAbs to human IL-7, presence it is possible to design specific methods of this cytokine's extraction from cultural or biological fluids. During previous stages of the study we have characterized MAbs panel for human IL-7. We have also conducted epitope mapping which is an important prerequisite of designing a highly effective method of immunoaffine chromatography (IACh).

Various publications (Nikolaenko et al., 2007; Yang et al., 2017; Çetin et al., 2019, Delaunay et al., 2020; Komar et al., 2019; DeCaprio et al., 2019) provide examples of IASs development. In all these works the main point lies in defining the process of "capture" of antibodies, which provide the best characteristics of the method improvement of conditions of specific sorption and desorption. At the same time almost no attention is paid to the choice of carrier used as a basis for IAS synthesis. In the majority of experiments sepharose is used as a sorbent, not so frequently sephacryl, micro-grained cellulose, etc. It is known that sepharose is a type of grained agarose, characterized by bigger pores that sephadex (Guo et al., 2019). These sorbents are modified depending on certain requirements to molecules separation; the modification includes the change of particles' size and the number of internal linking. At the same time all the achievements of modern chemistry of composite materials provide a wide range of potential carriers for creation of IACs. In our opinion, the most promising ones are various alkylsilanes and their derivatives, which are characterized with convenience of their obtainment basing on sol-gels, thermic and chemical persistence of the latter (Riboni et al., 2017). During selection of alkylsilane for our experiments we also considered possible toxicity of decay products of various alkylsilanes. As hydrolysis of the following compounds may result in releasing of corresponding alcohols, we immediately refused to use alkylsilanes, containing methyl groups. Comparative studies were conducted with sepharose 6B and tetraethoxysilane (TEOS) been used as carriers for IAC.

During the $1^{\text {st }}$ stage of research we have compared the efficiency of TEOS-based procedures of sol-gels' obtainment. The technology of sol-gel obtainment envisaged 2 stages: formation of sol-gel on the basis of corresponding alkylsilane and acid solution under the influence of ultrasound; introduction (immobilization) of MAbs to an organosilicone matrix. Criteria of efficiency of sol-gel formation were: optical transparency, speed of maturation, type of solution, and uniformity of formation of gel's 3D structure. Optimal terms and conditions of ultrasonic influence were defined via studying of parameters of MAbs immobilization on matrix i.e. the ratio of antibodies' residual activity in buffer solution was defined This TEOS-based study was conducted simultaneously with the similar study of kinetics of MAbs' immobilization on sepharose 6B. Reduction of anti-IL-7 titer of MAbs in ELISA proved the reduction of antibodies' concentration in buffer solution and consequently - their immobilization on matrix. During the conduction ELISA was diluted in ratio 1:400 and compared to control MAbs solution (Fig. 1)

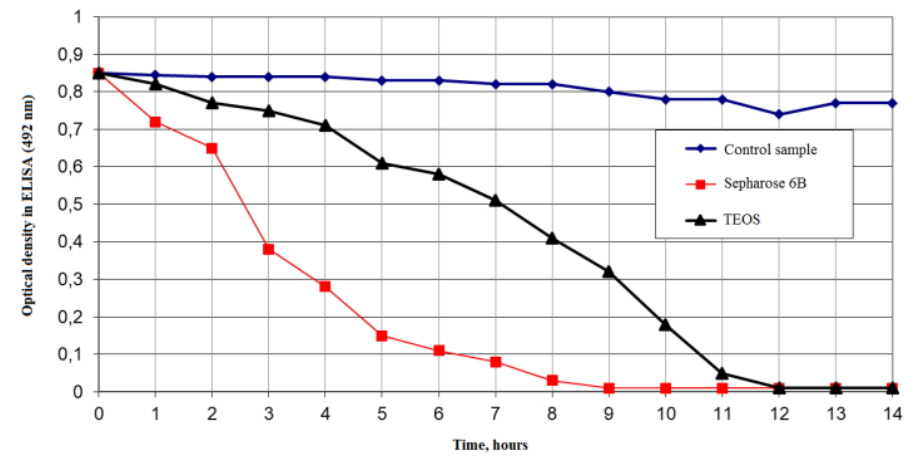

Figure 1 Dynamics of immobilization of anti-rIL-7 MAbs 325D2 on different sorbent matrices

As it is shown on Fig.2, 99\% of extraction (immobilization) of antibodies from reaction buffer is reached for both types of sorbents within 12 hours, which is acceptable from the technological aspect. As both Sepharose B6 and tetraethoksysilane showed acceptable dynamic parameters of MAbs immobilization further studies, dedicated to development of method of specific extraction of rIL-7, were conducted simultaneously for both immunoaffinity chromatographic columns.

Further researches on verification of the protocol of immunoaffinity chromatography were conducted for columns with different basic matrices and different MAbs, which are present in our laboratory (Table 1).

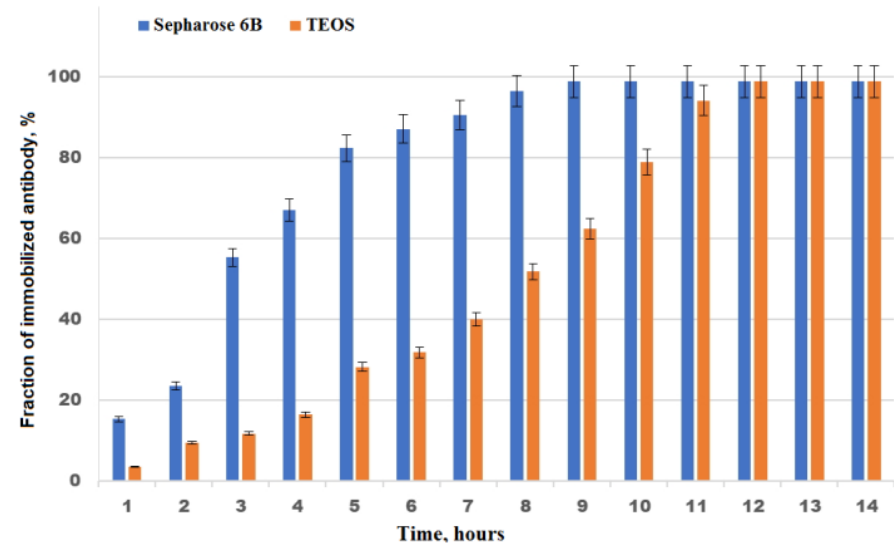

Figure 2 Change of fraction of immobilized anti-rIL-7 MAbs 325D2 on differen sorbent matrices during synthesis of immunoaffinity column

Table 1 Characteristics of MAbs against IL-7

\begin{tabular}{ccccc}
\hline MAb & $\begin{array}{c}\text { OD } \\
\text { ELISA }\end{array}$ & Isotype & $\begin{array}{c}\text { Titer in } \\
\text { cultural } \\
\text { fluid }^{\mathbf{1}}\end{array}$ & $\begin{array}{c}\text { Affinity } \\
\text { constant }^{\mathbf{1}} \mathbf{1 0}^{\mathbf{9}} \mathbf{M}^{\mathbf{1}}\end{array}$ \\
\hline $314 \mathrm{~B} 5$ & 2.571 & $\mathrm{IgG}_{2 \mathrm{a}}$ & $1: 1600$ & 16.0 \\
\hline $325 \mathrm{D} 2$ & 2.755 & $\mathrm{IgG}_{2 \mathrm{a}}$ & $1: 1600$ & 12.0 \\
\hline
\end{tabular}

In order to evaluate the efficiency of synthesized IACs we have used such parameters as binding activity of rIL-7 from buffer and purity of the rIL-7 preparation upon elution from the column of bound fraction. In this series of experiments, a certain list of solutions for elution, used by other researchers (Nikolaenko et al., 2007; Yang et al., 2017; Çetin et al., 2019; Delaunay et al., 2020; Komar et al., 2019; DeCaprio et al., 2019), in particular: McIlvaine buffer (CPB), $\mathrm{pH} 2.0-2.4,4 \mathrm{M}$ of $\mathrm{MgCl}_{2}$ solution and $8 \mathrm{M}$ of urea solution, $\mathrm{pH} 2.0-2.4$. 
Obtained experimental data concerning analytical characteristics of synthesized IACs are shown in Table 2 and Figure 3. Represented data confirm the acceptable level of extraction of target product (rIL-7) from buffer solution. It is worth mentioning that in case of IAC based on MAbs 325D2 results were better than in case of the one, basing on MAbs 314B5. In this series of experiments TEOS-base IAS has demonstrated a better level of rIL-7 extraction. Chromatographic purification option No.12 proved to be the most effective. It should be also noted that levels of extraction of target product in case with IACh, based on MAbs 325D2 (No. 4, 5, 6, 10, 11, 12) were higher than similar results, but when MAbs 314B5 (No. 1, 2, 3, 7, 8, 9) was used. Thus, average extraction level of rIL-7 for al sorbents with MAbs 325D2 and all elution options was $90.0 \%$, while for IACh, based on MAbs 325D2, the level was $92.8 \%$.

Table 2 Comparative characteristics of various immunoaffinity columns

\begin{tabular}{|c|c|c|c|c|c|c|}
\hline Sorbent matrix & MAb & Eluent & Variant & $\begin{array}{c}\text { Amount of rIL-7, put } \\
\text { on IAC, } \mu \mathrm{g}\end{array}$ & $\begin{array}{l}\text { Amount of rIL-7 in } \\
\text { fraction, not bound to } \\
\text { IAC, } \mu \mathrm{g}\end{array}$ & $\begin{array}{c}\text { Amount of rIL-7 in } \\
\text { eluat, } \mu \mathrm{g}\end{array}$ \\
\hline \multirow{6}{*}{ Sepharose 6B } & \multirow{3}{*}{ 314B5 } & $\mathrm{CPB}$ & 1 & 5 & $0.55 \pm 0.03$ & $4.45 \pm 0.22$ \\
\hline & & Urea & 2 & 5 & $0.48 \pm 0.02$ & $4.52 \pm 0.23$ \\
\hline & & $\mathrm{MgCl}_{2}$ & 3 & 5 & $0.47 \pm 0.02$ & $4.52 \pm 0.23$ \\
\hline & \multirow{3}{*}{$325 \mathrm{D} 2$} & $\mathrm{CPB}$ & 4 & 5 & $0.35 \pm 0.02$ & $4.65 \pm 0.23$ \\
\hline & & Urea & 5 & 5 & $0.33 \pm 0.02$ & $4.65 \pm 0.23$ \\
\hline & & $\mathrm{MgCl}_{2}$ & 6 & 5 & $0.32 \pm 0.02$ & $4.65 \pm 0.23$ \\
\hline \multirow{6}{*}{ Tetraethoxysilane } & \multirow{3}{*}{ 314B5 } & $\mathrm{CPB}$ & 7 & 5 & $0.51 \pm 0.03$ & $4.49 \pm 0.22$ \\
\hline & & Urea & 8 & 5 & $0.47 \pm 0.02$ & $4.53 \pm 0.23$ \\
\hline & & $\mathrm{MgCl}_{2}$ & 9 & 5 & $0.51 \pm 0.03$ & $4.49 \pm 0.22$ \\
\hline & \multirow{3}{*}{$325 \mathrm{D} 2$} & $\mathrm{CPB}$ & 10 & 5 & $0.39 \pm 0.02$ & $4.61 \pm 0.23$ \\
\hline & & Urea & 11 & 5 & $0.45 \pm 0.02$ & $4.54 \pm 0.23$ \\
\hline & & $\mathrm{MgCl}_{2}$ & 12 & 5 & $0.25 \pm 0.01$ & $4.75 \pm 0.24$ \\
\hline
\end{tabular}

Note. Here showed arithmetic means for 3 cycles of chromatography for each of the options and standard deviation

Practical application of synthesized IAC requires stability, which is stipulated by the following characteristics (Nikolaenko et al., 2007): firstly, the influence of multiple usage of column on the level of rIL-7 extraction; secondly, influence of various rIL-7 concentration's levels on the extraction process and thirdly - the possibility of deterging of immobilized MAbs during IACs deterging with various solutions.

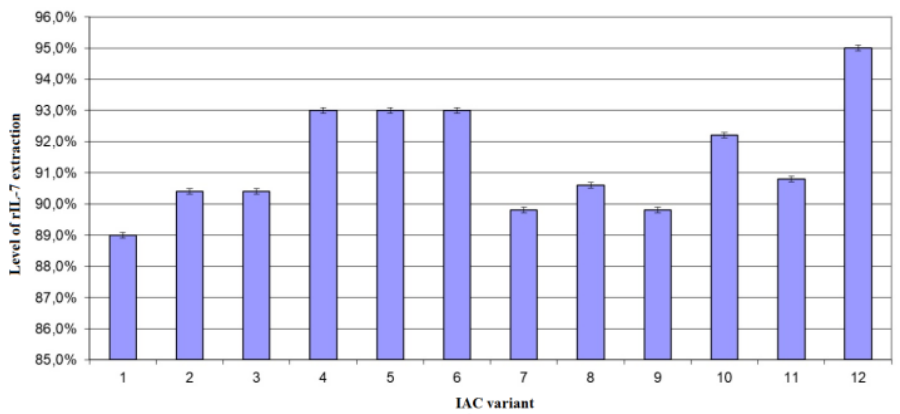

Figure 3 Levels of rIL-7 extraction from solution in different IAC variants and different conditions of elution

In order to estimate the stability of extraction rate of target matter we have conducted 25 cycles of chromatographic purification during IAC work, using two types of IAC (types No. 6 and 12, table 2) - based on sepharose 6 B and TEOS The results of conducted research, shown in Figure 4, prove that immunoaffinity column, based on sepharose $6 \mathrm{~B}$, is less stable in terms of IAC than the one, which is TEOS-based; within the first 11 cycles both columns were characterised by comparable values whilst within the period from $12^{\text {th }}$ to $17^{\text {th }}$ cycle there was a substantial reduction of sepharose-based column.

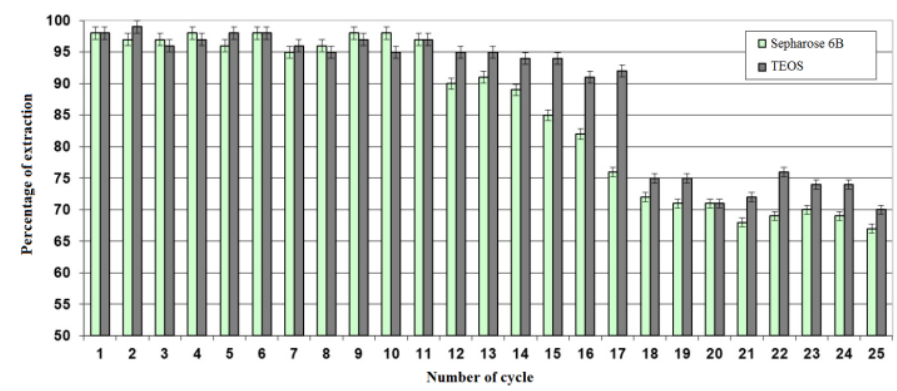

Figure 4 Ratio of rIL-7 extraction level in case of multiple use of column

It should be mentioned that acquired sorbents can be used both for scientific purposes and for practical ones (in industrial processes). Thus, the range of concentration of target matter, from which human rIL-7 is to be extracted, may be quite wide. Taking the following prerequisites into account, we think that it is worth studying the correlation between the level of rIL-7 extraction and its concentration in solution. The results we obtained (table 3 ) confirm the possibility of quite effective extraction of rIL-7 from quite diluted solutions for both columns.
Table 3 Ratio of rIL-7 extraction depending on its concentration in solution

\begin{tabular}{lccc}
$\begin{array}{l}\text { Volume of } \\
\text { solution, } \\
\text { ml }\end{array}$ & $\begin{array}{c}\text { Concentration of rIL-7 in } \\
\text { solution, } \boldsymbol{\mu g} / \mathbf{m l}\end{array}$ & \multicolumn{2}{c}{ Percentage of extraction, \% } \\
\cline { 3 - 4 } & 0.005 & 79 & Sepharose 6B \\
\hline 500 & 0.05 & 96 & 80 \\
\hline 50 & 0.5 & 97 & 96 \\
\hline 10 & 5 & 97 & 98 \\
\hline 1 & 20 & 98 & 97 \\
\hline 1 & & & \\
\hline
\end{tabular}

Estimation of the possibility of deterging of immobilized MAbs from synthesized IAC was conducted via UV-vis absorption spectroscopy (with the wavelength 280 $\mathrm{nm}$ ) during deterging of corresponding columns (options №№ 6 and 12, table 2) with a tenfold volume of phosphate buffer solution ( $\mathrm{pH} 7.2)$ and ethanol. The results obtained proved the absence of MAbs deterging from the columns of both types.

Purity of obtained preparation of rIL-7 was checked in terms of presence of residual proteins and impurities via reducing Polyacrylamide Gel Electrophoresis (Fig. 5).

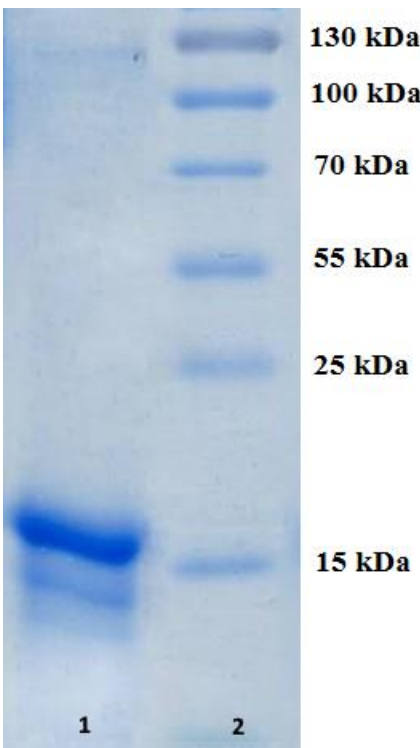

Figure 5 Electropherogram of rIL-7 preparation: 1 -rIL-7 preparation; 2 - MM markers $(130,100,70,55,25,15 \mathrm{kDa})$

\section{DISCUSSION}

Proteins for therapeutic purposes face serious requirements to purity, which is envisaged by the requirements of pharmacopoeias to purity of corresponding substances and officinal medicines. In case of substances' development (especially - of biotechnological origin) it is worth paying attention to its purpose, as various medicine undergo various requirements concerning the content of active 
pharmaceutical ingredient (API) and impurities, stipulated by API's degrading and technological factors (e.g., the presence of bacterial endotoxins, which is crucial for technologies using recombinant proteins, obtained via microbial synthesis Taking the aforementioned into account the goal of creating a highly specific method of recombinant proteins' purification, is of high demand (Lutsenko et al. 2017; Natochii et al. 2019).

The methods (Galkin et al., 2017a; Lutsenko et al.; Golembiovska et al., 2019) which we used and described in our technology, i.e. the methods of ion-exchange chromatography and gel-permeation HPLC provided the possibility to fulfill the requirements, stated in guidelines, in case of obtainment of non-injection drugs. In order to solve the case we had to use (as an additional stage) more specific methods, among which there is IACh (Altstein et al., 2001; Nikolaenko et al., 2005).

The scientific literature (Nikolaenko et al., 2007; Yang et al., 2017; Çetin et al., 2019; Delaunay et al., 2020; Komar et al., 2019; DeCaprio et al., 2019) present the results of the development of various IAS, which involve determining the optimal (rational) monoclonal antibodies (MAbs) from a particular panel and optimizing the conditions of sorption and desorption of the target substance. In this case, you can use one or more carriers to obtain immunoaffinity columns, because according to (Nikolaenko et al., 2007) this approach can also lead to positive results in terms of obtaining more efficient (better removal of the target substance) and more stable (more cycles of immunoaffinity column without significant reduction of its effectiveness) IAS

Based on the literature data (DeCaprio et al., 2019; Guo et al., 2019; Riboni et al., 2017), we decided to focus on two types of sorbents-bases for the development of our own immunoaffinity column - Sepharose 6B and tetraethoxysilane (TEOS). Synthesis and comparative characteristics of immunoaffinity columns - sepharosebased and TEOS-based - for specific extraction of rIL-7 were performed as a result of conducted work. The character of monoclonal antibodies' immobilization on the chosen sorbents was equivalent in terms of technological aspects. It was proven that IAC, which is based on TEOS and anti-IL-7 MAbs 325D2, is characterized by higher efficiency in terms of rIL-7 extraction. The best eluent was the solution of $4 \mathrm{M}$ of $\mathrm{MgCl}_{2}$. Synthesized IAC, which were sepharose-based and TEOS-based, are characterized by high levels of extraction (not less than $98 \%$ ) in a wide range of rIL-7 concentrations $\left(5 \times 10^{-3}-2 \times 10^{1} \mu \mathrm{g} / \mathrm{ml}\right)$, the IAC, which was based on sepharose $6 \mathrm{~B}$, was a little bit less stable in conditions of multiple repetitions of cycles (more than 12 cycles).

\section{CONCLUSIONS}

A highly specific method of rIL-7 purification was designed based on immunoaffinity chromatography. Various bases for immunoaffinity column and binding elements of rIL-7, based on monoclonal antibodies and solutions for elution, were studied. We have analyzed the efficacy of carriers during multistage purification. The sequence of conducted research allowed to define that the best purification results were obtained with the application of MAbs 325D2 binding agent, Tetraethoxysilane as a carrier and $4 \mathrm{M}$ of $\mathrm{MgCl}_{2}$ for elution. Conducted experiments also allowed to define that tetraethoxysilane used on a column basis can be used up to 15 successive cycles without losses of the final product's quality. As a result, we have obtained rIL-7 substance with purity of $98 \%$.

\section{REFERENCES}

Slyvka, A. V., \& Okunev, O. V. (2014). Molecular mechanisms of versatile biological activity of interleukin-7. Biopolymers and Cell, 30(5), 349-357. doi: http://dx.doi.org/10.7124/bc.0008B1

Grigorieva, S. M., Starosyla, D. B., Rybalko, S. L., Motronenko, V. V., ... Lutsenko, T. M. (2019). Effect of recombinant human interleukin-7 on Pseudomonas aeruginosa wound infection. The Ukrainian Biochemical Journal, 91(5), 7-15. doi: http://dx.doi.org/10.15407/ubj91.05.007

Galkin, O. Y., Lutsenko, T. M., Gorshunov, Y. V., ... Motronenko, V. V. (2017) Development of the method for microbiological purity testing of recombinan human interleukin-7-based product. The Ukrainian Biochemical Journal, 89(3), 52-59. doi: http://dx.doi.org/10.15407/ubj89.03.052

Lutsenko, T. N., Kovalenko, M. V., \& Galkin, O. Y. (2017). Validation of biological activity testing procedure of recombinant human interleukin-7. The Ukrainian Biochemical Journal, 89(1), 82-89. doi: http://dx.doi.org/10.15407/ubj89.01.082

Natochii, T., \& Motronenko, V. (2019). Comparative Characteristics of Biotechnological Approaches to Obtaining Recombinant Human Cytokines in Bacterial Expressing Systems. Innovative Biosystems and Bioengineering, 3(3), 128-145. doi: http://dx.doi.org/10.20535/ibb.2019.3.3.170150

Sokol, A. A., Grekov, D. A., Yemets, G. I., Galkin, A. Y., Shchotkina, N. V., Dovghaliuk, A. A., ... Yemets, I. M. (2020). Comparison of bovine pericardium decellularization protocols for production of biomaterial for cardiac surgery. Biopolymers and Cell, 36(5), 392-403. doi: http://dx.doi.org/10.7124/bc.000A3C Galkin A., Komar A., Gorshunov Yu., Besarab A., Soloviova V. New monoclona antibodies to the prostate-specific antigen: obtaining and studying biological properties. Journal of Microbiology, Biotechnology and Food Sciences, 9(3), 573 577. doi: http://dx.doi.org/10.15414/jmbfs.2019/20.9.3.573-577
Nikolaenko, I.V., Goncharenko, V.S., Shimko, N.N., Galkin, A.Yu. Isolation of surface antigen of hepatites B virus // Ukrain'skyi Biokhimichnyi Zhurnal, 2007, 79(2), стр. 114-122.

Motronenko V., Lutsenko T., Galkin A., Gorshunov Y., Solovjova V. Optimization of the culture medium composition to increase the biosynthesis of recombinant human interleukin-7 in Escherichia coli. Journal of Microbiology, Biotechnology and Food Sciences, 9(4), 761-768. doi http://dx.doi.org/10.15414/jmbfs.2020.9.4.761-768

Pokynbroda, T., Karpenko, I., Midyana, H., \& Karpenko, O. (2019). Isolation of Surfactants Synthesized by the Pseudomonas Bacteria and Study of Their Properties. Innovative Biosystems and Bioengineering, 3(2), 70-76. doi http://dx.doi.org/10.20535/ibb.2019.3.2.165838

Galkin, O. Y., Besarab, A. B., \& Lutsenko, T. N. (2017). Characteristics of enzyme-linked immunosorbent assay for detection of $\mathrm{IgG}$ antibodies specific to Chlamydia trachomatis heat shock protein (HSP-60). The Ukrainian Biochemica

Journal, 89(1), 22-30. doi: http://dx.doi.org/10.15407/ubj89.01.022

Altstein, M., Bronshtein, A., Glattstein, B., Zeichner, A., Tamiri, T., \& Almog, J. (2001). Immunochemical Approaches for Purification and Detection of TNT Traces by Antibodies Entrapped in a Sol-Gel Matrix. Analytical Chemistry, 73(11), 2461-2467. doi: http://dx.doi.org/10.1021/ac001376y

Sokol, A., Grekov, D., Yemets, G., Galkin, O., ... Shchotkina, N. (2020). Biocompatiblibility analysis of the decellularized bovine pericardium. Cell and Organ Transplantology, 8(2). doi: http://dx.doi.org/10.22494/cot.v8i2.110

Yang, F., Liao, X., Tian, Y., \& Li, G. (2017). Exosome separation using microfluidic systems: size-based, immunoaffinity-based and dynamic methodologies. Biotechnology Journal, 12(4), 1600699. doi http://dx.doi.org/10.1002/biot.201600699

Çetin, K., \& Denizli, A. (2019). Immunoaffinity microcryogels for purification of transferrin. Journal of Chromatography B, 1114-1115, 5-12. doi: http://dx.doi.org/10.1016/j.jchromb.2019.03.017

Delaunay, N., Combès, A., \& Pichon, V. (2020). Immunoaffinity Extraction and Alternative Approaches for the Analysis of Toxins in Environmental, Food or Biological Matrices. Toxins, 12(12), $795 . \quad$ doi http://dx.doi.org/10.3390/toxins12120795

Komar, A., Kozerecka, O., Besarab, O., \& Galkin, A. (2019). Development and Validation of a Highly Informative Immuno-Enzymatic Analysis for the Determination of Free Prostat-Specific Antigen. Innovative Biosystems and Bioengineering, 3(4), 220-231.

http://dx.doi.org/10.20535/ibb.2019.3.4.185877

DeCaprio, J., \& Kohl, T. O. (2019). Tandem Immunoaffinity Purification Using Anti-FLAG and Anti-HA Antibodies. Cold Spring Harbor Protocols, 2019(2). doi: http://dx.doi.org/10.1101/pdb.prot098657

Guo, H., Zhang, W., Jiang, Y., Wang, H., Chen, G., \& Guo, M. (2019). Physicochemical, Structural, and Biological Properties of Polysaccharides from Dandelion. $\quad$ Molecules, $24(8), \quad 1485$. 1485. http://dx.doi.org/10.3390/molecules24081485

Riboni, N., Magrini, L., Bianchi, F., Careri, M., \& Cappiello, A. (2017). Sol-gel coated ion sources for liquid chromatography-direct electron ionization mass spectrometry. Analytica Chimica Acta, 978, 35-41. doi http://dx.doi.org/10.1016/j.aca.2017.04.026

Golembiovska O.I., Galkin A.Yu., Besarab A.B. Development and validation of a dissolution test for ursodeoxycholic acid and taurine from combined formulation. Scientific Study \& Research - Chemistry \& Chemical Engineering, Biotechnology, Food Industry. 2019, 20 (3), pp. 377 - 394

Nikolaenko IV, Galkin AIu, Raevskaia GE, Kas'ianenko TV, Nereshchenko MI, Donskaia ES, Spivak NIa. Preparation of monoclonal antibodies to the Fcfragment of human IgG and the use of their based immunoenzyme conjugates. Klin Lab Diagn. 2005;(11):8-11. 